\title{
ESPACIALIDADE DE ATRIBUTOS DE SOLOS CULTIVADOS COM CANA-DE-AÇÚCAR NO PONTAL DO
} PARANAPANEMA, SP

Marcelo Rodrigo Alves ${ }^{1}$, Luiz Paulo Montenegro de Miranda ${ }^{2}$, Paulino Taveira Souza ${ }^{2}$, Anne Caroline Rocha ${ }^{2}$, Karla Nascimento Sena ${ }^{2}$, Maria Julia Betiolo Troleis, Rafael Montanari ${ }^{2}$

${ }^{1}$ Universidade do Oeste Paulista - UNOESTE, Presidente Prudente, SP. ${ }^{2}$ Universidade Estadual Paulista - UNESP. Email: marceloalves@unoeste.br

\section{RESUMO}

A pesquisa teve como objetivo organizar e analisar um banco de dados geoespacial de informações pedológicas e aplicar técnicas de geoestatística para avaliar a dependência espacial de atributos físicos e químicos do solo. Para tanto, buscou-se confeccionar uma base de dados com 473 pontos amostrais pertencentes a uma grade não regular, coletados em duas profundidades $(0,00$ a $0,25 \mathrm{~m}$ e 0,25 a 0,50m), devidamente georreferenciados. As amostras foram coletadas em uma região com predominância de Latossolos e Argissolos, na sua maioria, muito arenosos, pouco ácidos, pobres em argila e de grande profundidade, sob a cultura da cana-de-açúcar em diferentes idades de corte, sendo a amostragem realizada no meio da entrelinha da cultura, com o auxílio de um trado holandês e posteriormente submetido às determinações analíticas químicas e físicas em laboratório. Baseado nesses resultados determinou-se, ainda, o potencial de produção de cana de açúcar para a região do Pontal do Paranapanema, SP. Em seguida realizou-se a análise descritiva dos dados, estabelecendo-se correlações lineares, simples e múltiplas, entre os atributos. Foram modelados semivariogramas, obtendo-se as respectivas krigagens e validações cruzadas. Também foram estabelecidas as cokrigagens de interesse. Os teores de $\mathrm{Ca}, \mathrm{Mg}$, $\mathrm{K}$ e $\mathrm{MO}$ apresentaram forte dependência espacial na camada superficial. A variável ambiente relacionou-se negativamente com todos os atributos e camadas, exceto argila, areia fina e alumínio.

Palavras-chave: geoestatística; dependência espacial; granulometria do solo; Saccharum officinarum; fertilidade do solo.

\section{SPATIALITY OF ATTRIBUTES OF SOILS CULTIVATED WITH SUGAR CANE IN PONTAL DO PARANAPANEMA, SP}

\begin{abstract}
The present work aimed to organize and analyze a geospatial database of pedological information and to apply geostatistics techniques to evaluate the spatial dependence of physical and chemical attributes of the soil. In order to do so, a database was designed with 473 sampling points belonging to a non-regular grid, collected at two depths, 0.00 to $0.25 \mathrm{~m}$, and 0.25 to $0.50 \mathrm{~m}$, duly georeferenced. The samples were collected in a region with predominance of Oxisols and Ultisols, mostly very sandy, low acid, clay poor and of great depth, under sugarcane culture at different ages of cut, being the sampling performed in the middle of the culture line, with the help of a Dutch translator and later submitted to chemical and physical analytical determinations in the laboratory. Based on these results, the sugarcane production potential for the study region was also determined. Then, the descriptive analysis of the data was performed, establishing simple and multiple linear correlations between the attributes. Semivariograms were modeled, obtaining the respective krigagens and cross validations. Cokrigagens of interest were also established. The attributes $\mathrm{Ca}$, $\mathrm{Mg}, \mathrm{K}$ and $\mathrm{MO}$ presented strong spatial dependence on the surface layer. The environment variable was negatively related to all attributes and layers except clay, fine sand and aluminum.

Keywords: geostatistics; spatial dependence; soil granulometry; Saccharum officinarum; soil fertility.
\end{abstract}




\section{INTRODUÇÃO}

Segundo dados do monitoramento da cana-de-açúcar (CANASAT) em 2013 os plantios de cana-de-açúcar na região do Pontal do Paranapanema, que inclui 32 municípios de estado de São Paulo, ocuparam uma área superior a 320.240 hectares. Este valor representou menos de $17,4 \%$ da área total do Pontal, indicando que esta área é pouco explorada com a cana-de-açúcar e possui grande potencial de expansão da cultura.

No contexto de produção e manejo do solo, a textura constitui-se num dos atributos físicos mais estáveis e representa a distribuição quantitativa das partículas sólidas minerais quanto ao tamanho. Sua grande estabilidade faz com que essa seja considerada um atributo de grande importância na descrição, identificação e principalmente na classificação dos solos (FERREIRA, 2010). A fração areia é constituída principalmente por quartzo, tem reduzida capacidade de retenção a água e reduzida atividade química. Por outro lado, essas partículas de maior diâmetro facilitam a drenagem e a aeração do solo. Enquanto a fração argila influi acentuadamente em propriedades e atributos do solo por apresentar características específicas devido ao seu tamanho, o que resulta em alta reatividade química (MEURER, 2007).

Apesar de sua pequena proporção nos solos minerais tropicais, a matéria orgânica (MO), desempenha grande influência sobre vários atributos físicos, químicos e biológicos do solo e exerce várias funções nos ecossistemas terrestres (SILVA; MENDONÇA, 2007). A acidez do solo é resultado do equilíbrio entre a atividade de $\mathrm{H}^{+}$na solução e a concentração de $\mathrm{H}^{+}$e de $\mathrm{Al}^{3+}$ adsorvidos na capacidade de troca catiônica (CTC) do solo. O conhecimento da relação entre a acidez do solo e o crescimento e desenvolvimento das plantas é fundamental para o estabelecimento de práticas de correção do solo, que visem à maior eficiência na aplicação de insumos e no uso dos sistemas de produção agrícola, associando-os ao uso eficiente dos recursos naturais (SOUSA et al., 2007).

A produção de cana-de-açúcar depende das condições químicas e físico-hídricas das camadas superficiais e subsuperficiais dos solos, juntamente com as condições climáticas, formando os chamados ambientes de produção. O manejo básico da cultura nos ambientes considera que é feito corretamente o preparo do solo, plantio e colheita; além da escolha da variedade em relação aos ambientes; doses adequadas de corretivos e fertilizantes; controle local evitando a erosão e que não ocorram impedimentos químicos, físicos e biológicos no solo que restringem $O$ desenvolvimento do sistema radicular (PRADO; PÁDUA JÚNIOR, 2006).

A variabilidade espacial, horizontal e vertical, de diversos atributos do solo é dependente de fatores de sua formação podendo estar relacionado com o seu manejo (SOUZA et al., 2001). Montanari et al. (2005) afirmaram que a variabilidade dos atributos do solo é influenciada pela sua localização na paisagem ou no declive, mesmo que esse seja de pequena expressão. Silva et al. (2015) ressaltaram a importância da incorporação do conhecimento da variabilidade espacial dos atributos do solo ao processo de produção agrícola. Assim, a partir do ano 2000 , diversos trabalhos têm demonstrado a importância do conhecimento da variabilidade espacial dos atributos do solo em sistemas de produção agrícola (GAZOLA et al., 2017).

Diante disso, objetivou-se organizar e analisar um banco de dados geoespacial de informações pedológicas e aplicar técnicas de geoestatística a fim de avaliar a dependência espacial dos atributos do solo estudados.

\section{MATERIAL E MÉTODOS}

A área de estudo está localizada entre as latitudes -22.7112 e $-21.4710 \mathrm{~S}$ e longitudes 53.1127 e $-51.3616 \mathrm{~W}$ que compreendem uma área aproximada (não continua), de 25.000 hectares, ocupadas com a cultura da cana-deaçúcar. Essa área está distribuída por quatro cidades na região do Pontal do Paranapanema, Estado de São Paulo, sendo elas: Estrela do Norte, Mirante do Paranapanema, Pirapozinho e Sandovalina.

Na região predominam dois tipos de solos sendo, os Latossolos e os Argissolos, que interagem com outras formações em menores proporções. Esses solos são, na sua maioria, muito arenosos, pouco ácidos, pobres em argila e de grande profundidade, consequentemente apresentando alta drenagem (MENEGUETTE, 2001).

Veloso et al. (1991) descreveram que a vegetação da região é classificada como "Floresta Estacional Semidecidual" inserida nos domínios da Mata Atlântica, sendo por isso popularmente chamada de "Mata Atlântica do Interior". Verifica-se também algumas manchas de cerrado e a presença de banhados nas áreas próximas aos rios (SMA-SP, 1999). 
Para confecção da base de dados foram utilizados 473 pontos amostrais pertencentes a uma grade não regular, coletados em duas profundidades $(0,00$ a $0,25 \mathrm{~m}$ e 0,25 a $0,50 \mathrm{~m})$, dos quais são conhecidas as coordenadas geográficas por meio do receptor Garmin ETrex 30. Estas amostras de solo foram coletadas sob a cultura da cana-de-açúcar em diferentes idades de corte, sendo a amostragem realizada no meio da entrelinha da cultura, com o auxílio de um trado holandês e posteriormente submetido às determinações analíticas químicas e físicas em laboratório.

Os dados granulométricos de teores de argila (ARG), areia fina (AF) e areia grossa (AG) foram avaliados por meio do método da pipeta (EMBRAPA, 1997). Para os atributos químicos foram analisados os teores de potencial hidrogeniônico em água $(\mathrm{pH})$, fósforo $(\mathrm{P})$, potássio $(\mathrm{K})$, cálcio $(\mathrm{Ca})$, magnésio $(\mathrm{Mg})$, alumínio (Al), hidrogênio $(H)$ e matéria orgânica (MO), conforme metodologia descrita por Raij e Quaggio (1983).

Para cada ponto amostrado também foi fornecido o potencial de produção para a cultura da cana-de-açúcar, classificados segundo metodologia descrita em Joaquim et al. (1997). Os ambientes de produção foram classificados numericamente para análise dos dados de acordo com a metodologia seguida por Soria (2014), onde os melhores ambientes receberam as notas mais altas e os piores as notas mais baixas, em uma escala de 0 a 10. Assim, o ambiente " 1 " receberá nota variando de 10 a 8 ; o ambiente " 2 " de 8 a 6; o ambiente " 3 " de 6 a 4; o ambiente " 4 " de 4 a 2 , e; o ambiente " 5 " receberá nota variando de 2 a 0 . Sendo utilizado o valor central de cada intervalo para substituição das classes dos ambientes.

Para cada atributo estudado realizou-se a análise descritiva auxiliada pela estatística clássica. Utilizando-se o SAS, foram calculados a média, mediana, moda, valores mínimos e máximos, desvio padrão, coeficiente de variação, curtose e assimetria (SCHLOTZHAVER; LITTEL, 1997), além de executar a análise da distribuição de frequência. Desta forma, para testar a hipótese de normalidade, dos atributos (ARG, AF, $A G, p H, P, K, C a, M g, A l, H$ e $M O)$, utilizou-se o teste de Shapiro e Wilk (1965) a 1\%. Construíramse matrizes de correlação, com o objetivo de efetuar as regressões lineares para as combinações, duas a duas, entre todos os atributos dos solos estudados e os ambientes de produção. Com o intuito de estudar a correlação linear entre estes, buscou-se selecionar aqueles que sejam semelhantes, e que provavelmente poderão apresentar semivariogramas cruzados e, portanto, mapas de cokrigagem.

Para cada atributo foi analisada a dependência espacial pelo cálculo do semivariograma, com base nas pressuposições de estacionaridade da hipótese intrínseca, pelo uso do pacote computacional $\mathrm{GS}^{+}$(ROBERTSON, 2004).

O ajuste do semivariograma, em função de seus modelos, foi efetuado pela seleção inicial de: a) o maior coeficiente de determinação $\left(r^{2}\right)$; b) a menor soma dos quadrados dos resíduos $(\mathrm{SQR})$, e c) o maior avaliador da dependência espacial (ADE). A decisão final do modelo representante do ajuste foi por meio da validação cruzada, assim como também para a definição do tamanho da vizinhança que proporcionará a melhor malha de krigagem. Para cada atributo foram relacionados o efeito pepita $\left(C_{0}\right)$, alcance (A) e o patamar $\left(\mathrm{C}_{\mathrm{o}}+\mathrm{C}\right)$. A análise do avaliador da dependência espacial (ADE) foi conforme sugestões de Cambardella et al. (1994), modificada por Robertson (2004) conforme a seguinte expressão:

$$
A D E=\left[C C+C_{o}\right] 100 .
$$

Sendo: ADE é o avaliador da dependência espacial; $C$ é a variância estrutural; $C_{0}+C$ é 0 patamar.

Por outro lado, sabe-se que a validação cruzada é uma ferramenta destinada a avaliar modelos alternativos de semivariogramas que efetuarão a krigagem. Assim, trabalhando-se na obtenção do número ideal de vizinhos, foram obtidos, por meio da interpolação por krigagem, os mapas de krigagem para a interpretação e o detalhamento da variabilidade espacial dos atributos pesquisados.

\section{RESULTADOS E DISCUSSÃO}

Os resultados da estatística descritiva para os atributos físico-químicos do solo constam no quadro 1 . Os atributos avaliados, tanto físicos como químicos, não apresentaram distribuição de frequência do tipo normal. De acordo com Cressie (1991), a normalidade não é uma exigência da Geoestatística, sendo conveniente que o gráfico de distribuição de frequência não apresente caudas muitos alongadas, o que poderia comprometer as análises, fato não observado neste estudo.

A variabilidade dos atributos está relacionada com a amplitude do coeficiente de 
variação, segundo Freddi et al. (2006). Os menores valores de CV para os atributos químicos, foram observados nas duas camadas, respectivamente, para $\mathrm{pH} 1(8,6 \%)$ e $\mathrm{pH} 2(10,2 \%)$ (Quadro 1). Dessa forma, os maiores valores de CV ocorreram para Al1 e Al2 para as duas camadas, respectivamente, 196,7 e $122,2 \%$ seguidos de potássio, K1 e K2, na ordem, 118,2 e $122,2 \%$. A magnitude do coeficiente de variação pode ser classificada em classes, como, baixa ( $C V \leq 10)$, média $(10 \%<\mathrm{CV} \leq 20 \%)$, alta $(20 \%<C V \leq 30 \%)$ e muito alta (CV $>30 \%)$ conforme Pimentel-Gomes e Garcia (2002). 


\begin{tabular}{|c|c|c|c|c|c|c|c|c|c|c|}
\hline \multirow{3}{*}{ Atributo ${ }^{\text {(a) }}$} & \multicolumn{10}{|c|}{ Medidas estatísticas descritivas } \\
\hline & \multirow{2}{*}{ Média } & \multirow{2}{*}{ Mediana } & \multicolumn{2}{|c|}{ Valor } & \multirow{2}{*}{$\begin{array}{l}\text { Desvio } \\
\text { Padrão }\end{array}$} & \multicolumn{3}{|c|}{ Coeficiente } & \multicolumn{2}{|c|}{$\begin{array}{c}\text { Probabilidade } \\
\text { do teste }^{(\mathbf{b})}\end{array}$} \\
\hline & & & Mínimo & Máximo & & Variação (\%) & Curtose & Assimetria & $\operatorname{Pr}<w$ & DF \\
\hline \multicolumn{11}{|c|}{ Atributos físicos do solo } \\
\hline ARG1 & 18,624 & 18,000 & 2,5 & 57,5 & 8,498 & 45,6 & 3,726 & 1,293 & 0,000 & IN \\
\hline AF1 & 45,311 & 45,700 & 12,9 & 72,5 & 11,189 & 24,6 & $-0,052$ & $-0,268$ & 0,001 & IN \\
\hline AG1 & 29,849 & 27,900 & 6,3 & 70,0 & 12,739 & 42,6 & 0,1285 & 0,659 & 0,000 & IN \\
\hline ARG2 & 23,296 & 23,000 & 9,5 & 58,5 & 7,046 & 30,2 & 3,055 & 1,082 & 0,000 & IN \\
\hline AF2 & 42,176 & 42,700 & 11,7 & 70,8 & 11,207 & 26,5 & $-0,002$ & $-0,273$ & 0,001 & IN \\
\hline AG2 & 26,193 & 24,500 & 4,9 & 57,3 & 11,202 & 42,7 & $-0,055$ & 0,557 & 0,000 & IN \\
\hline \multicolumn{11}{|c|}{ Atributos químicos do solo } \\
\hline pH $\mathrm{H}_{2} \mathrm{O} 12$ & 6,146 & 6,200 & 4,8 & 7,5 & 0,529 & 8,6 & 0,059 & $-0,292$ & 0,001 & IN \\
\hline P1 & 6,658 & 4,900 & 1,2 & 30,9 & 4,323 & 64,9 & 5,664 & 2,075 & 0,000 & IN \\
\hline K1 & 0,452 & 0,200 & 0,0 & 3,1 & 0,535 & 118,2 & 5,717 & 2,176 & 0,000 & IN \\
\hline Ca1 & 1,728 & 1,300 & 0,4 & 6,4 & 1,194 & 69,0 & 1,926 & 1,438 & 0,000 & IN \\
\hline Mg1 & 0,782 & 0,700 & 0,1 & 2,2 & 0,454 & 58,1 & 0,210 & 0,905 & 0,000 & IN \\
\hline Al1 & 0,071 & 0,000 & 0,0 & 0,8 & 0,141 & 196,7 & 6,201 & 2,448 & 0,000 & IN \\
\hline H1 & 1,649 & 1,600 & 0,5 & 4,0 & 0,559 & 33,9 & 2,620 & 1,315 & 0,000 & IN \\
\hline Mo1 & 1,029 & 1,000 & 0,5 & 2,2 & 0,332 & 32,2 & 0,030 & 0,698 & 0,000 & IN \\
\hline $\mathrm{pH} \mathrm{H} \mathrm{H}_{2} \mathrm{O} 22$ & 5,789 & 5,800 & 4,2 & 7,3 & 0,590 & 10,2 & $-0,561$ & $-0,096$ & 0,002 & IN \\
\hline P2 & 4,525 & 3,800 & 0,7 & 13,4 & 2,320 & 51,2 & 2,198 & 1,475 & 0,000 & IN \\
\hline K2 & 0,266 & 0,200 & 0,0 & 2,7 & 0,318 & 119,3 & 16,448 & 3,161 & 0,000 & IN \\
\hline $\mathrm{Ca} 2$ & 1,113 & 0,800 & 0,3 & 5,6 & 0,863 & 77,5 & 6,298 & 2,268 & 0,000 & IN \\
\hline Mg2 & 0,484 & 0,400 & 0,1 & 1,9 & 0,307 & 63,5 & 3,530 & 1,653 & 0,000 & IN \\
\hline Al2 & 0,179 & 0,100 & 0,0 & 1,0 & 0,219 & 122,2 & 1,292 & 1,262 & 0,000 & IN \\
\hline $\mathrm{H} 2$ & 1,984 & 1,800 & 0,9 & 5,3 & 0,735 & 37,0 & 3,085 & 1,611 & 0,000 & IN \\
\hline MO2 & 0,787 & 0,700 & 0,4 & 1,5 & 0,224 & 28,4 & $-0,149$ & 0,720 & 0,000 & IN \\
\hline AMB & 3,604 & 4,000 & 1,0 & 5,0 & 0,946 & 26,2 & 0,528 & $-0,717$ & 0,000 & IN \\
\hline
\end{tabular}

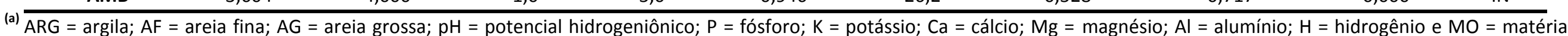

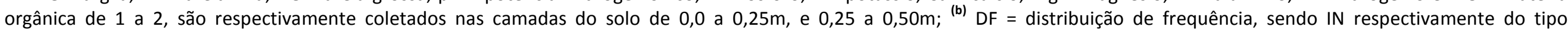
indeterminada.

Colloquium Agrariae, v. 14, n.2, Abr-Jun. 2018, p. 81-97. DOI: 10.5747/ca.2018.v14.n2.a209 
As correlações foram significativas entre a argila com os demais atributos avaliados, exceto com o teor de alumínio (Quadro 2). Esta se relaciona positivamente com $\mathrm{pH}$, e teores de fósforo, potássio, cálcio, magnésio, hidrogênio e matéria orgânica, sendo que o último atributo citado apresenta o maior valor entre as correlações, explicando $46,4 \%$ do comportamento da argila. Argila e matéria orgânica são os principais responsáveis por retenção de cargas nos solos (MEURER, 2007; CARNEIRO et al., 2008), assim, a relação entre os atributos supracitados está de acordo com demais estudados encontrados na literatura (SORIA, 2014; DALCHIAVON et al., 2013; ARAÚJO et al., 2016). 
Quadro 2. Matriz de correlação linear simples entre os atributos físico-químicos da camada 0,00 a 0,25m de solos cultivados com cana-de-açúcar.

\begin{tabular}{|c|c|c|c|c|c|c|c|c|c|c|c|}
\hline \multirow[t]{2}{*}{ Atributos $^{(a)}$} & \multicolumn{11}{|c|}{ Coeficiente de correlação $^{(b)}$} \\
\hline & ARG1 & AF1 & AG1 & pH 1 & P1 & K1 & Ca1 & Mg1 & Al1 & H1 & MO1 \\
\hline AF1 & $-0,354^{* *}$ & - & - & - & - & - & - & - & - & - & - \\
\hline AG1 & $-0,568^{* *}$ & $-0,565^{* *}$ & - & - & - & - & - & - & - & - & - \\
\hline pH 1 & $0,141^{* *}$ & $-0,016$ & $-0,111^{*}$ & - & - & - & - & - & - & - & - \\
\hline P1 & $0,099^{*}$ & $-0,002$ & $-0,085$ & $0,134^{* *}$ & - & - & - & - & - & - & - \\
\hline K1 & $0,101 *$ & $-0,082$ & $-0,017$ & 0,194 & 0,113 & - & - & - & - & - & - \\
\hline Ca1 & $0,336^{* *}$ & $-0,110^{*}$ & $-0,201^{* *}$ & $0,408^{* *}$ & $0,164^{* *}$ & $0,327^{* *}$ & - & - & - & - & - \\
\hline Mg1 & $0,348^{* *}$ & $-0,117^{* *}$ & $-0,203^{* *}$ & $0,438^{* *}$ & $0,250^{* *}$ & $0,336^{* *}$ & $0,769^{* *}$ & - & - & - & - \\
\hline Al1 & $-0,055$ & 0,003 & 0,047 & $-0,612^{* *}$ & $-0,142^{* *}$ & $-0,150^{*}$ & $-0,340^{* *}$ & $-0,412^{* *}$ & - & - & - \\
\hline H1 & $0,122^{* *}$ & $-0,202^{* *}$ & 0,069 & $-0,535^{* *}$ & $-0,073$ & 0,054 & $-0,095^{*}$ & $-0,124^{* *}$ & $0,347^{* *}$ & - & - \\
\hline M01 & $0,464^{* *}$ & $-0,097^{*}$ & $-0,324^{* *}$ & 0,056 & $0,224^{* *}$ & $0,345^{* *}$ & $0,464^{* *}$ & $0,452^{* *}$ & $-0,063$ & $0,266^{* *}$ & - \\
\hline Amb & $-0,541^{* *}$ & $0,245^{* *}$ & $0,263^{* *}$ & $-0,379^{* *}$ & $-0,133^{* *}$ & $-0,356^{* *}$ & $-0,593^{* *}$ & $-0,547^{* *}$ & $0,295^{* *}$ & 0,089 & $-0,377^{* *}$ \\
\hline
\end{tabular}

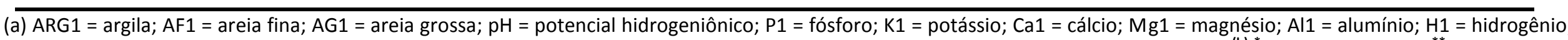

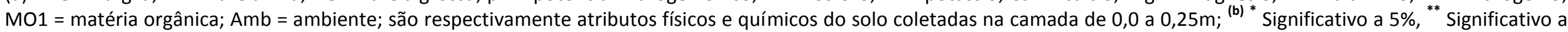
$1 \%$. 
Os atributos físicos AF1 e AG1 tem relação inversamente proporcional à argila, pois quanto mais argila, menor foram os valores de AG1 e AF1 conforme proporção estabelecida através de analises de textura. Corroborando, os valores de correlação entre AF1 e AG1 apresentam comportamento inversamente proporcional aos teores de cálcio, magnésio, matéria orgânica e o ambiente em ambas as profundidades (Quadro 3). A fração areia é constituída principalmente por quartzo, tem reduzida capacidade de retenção a água e reduzida atividade química enquanto a fração argila influi acentuadamente em atributos do solo por apresentar características específicas devido à alta reatividade química (MEURER, 2007), evidenciando o que foi observado no presente trabalho.
$\mathrm{O}$ pH apresentou correlação direta com fósforo, cálcio e magnésio, ou seja, a medida que o $\mathrm{pH}$ aumenta, estes nutrientes também têm teores elevados. Oposto a isto, alumínio $\left(-0.612^{* *}\right)$, hidrogênio $\left(-0.535^{* *}\right)$ e ambiente $\left(-0.379^{* *}\right)$ aumentam conforme $\mathrm{o} \mathrm{pH}$ do solo é reduzido, elevando a acidez do solo, fato indesejado para o cultivo. $O$ conhecimento da relação entre a acidez do solo e o crescimento e desenvolvimento das plantas é fundamental para o estabelecimento de práticas de correção do solo que visem à maior eficiência dos sistemas de produção agrícola e ao uso eficiente dos recursos naturais (SOUSA et al., 2007). 


\begin{tabular}{|c|c|c|c|c|c|c|c|c|c|c|c|}
\hline \multirow{2}{*}{ Atributos $^{(a)}$} & \multicolumn{11}{|c|}{ Coeficiente de correlaçãoo $^{(b)}$} \\
\hline & ARG2 & AF2 & AG2 & pH 2 & $\mathbf{P 2}$ & K2 & $\mathrm{Ca} 2$ & Mg2 & Al2 & H2 & MO2 \\
\hline AF2 & $-0,355^{* *}$ & - & - & - & - & - & - & - & - & - & - \\
\hline AG2 & $-0,447^{* *}$ & $-0,507^{* *}$ & - & - & - & - & - & - & - & - & - \\
\hline pH 2 & $0,143^{* *}$ & $-0,095^{*}$ & $-0,063$ & - & - & - & - & - & - & - & - \\
\hline $\mathbf{P 2}$ & 0,001 & 0,045 & $-0,118^{* *}$ & $0,165^{* *}$ & - & - & - & - & - & - & - \\
\hline K2 & 0,006 & $-0,103^{*}$ & 0,053 & $0,181^{* *}$ & 0,069 & - & - & - & - & - & - \\
\hline $\mathrm{Ca} 2$ & $0,451^{* *}$ & $-0,191^{* *}$ & $-0,263^{* *}$ & $0,472^{* *}$ & $0,215^{* *}$ & $0,193^{* *}$ & - & - & - & - & - \\
\hline Mg2 & $0,330^{* *}$ & $-0,152^{* *}$ & $-0,217^{* *}$ & $0,525^{* *}$ & $0,232^{* *}$ & $0,194^{* *}$ & $0,746^{* *}$ & - & - & - & - \\
\hline $\mathrm{Al} 2$ & $-0,052$ & 0,01 & 0,026 & $-0,719^{* *}$ & $-0,224^{* *}$ & $-0,138^{* *}$ & $-0,410^{* *}$ & $-0,480^{* *}$ & - & - & - \\
\hline $\mathrm{H} 2$ & $0,157^{* *}$ & $-0,196^{* *}$ & 0,043 & $-0,464^{* *}$ & $-0,072$ & 0,039 & $-0,123^{* *}$ & $-0,177^{* *}$ & $0,432^{* *}$ & - & - \\
\hline MO2 & $0,411^{* *}$ & $-0,03$ & $-0,365^{* *}$ & $-0,027$ & $0,233^{* *}$ & $0,292^{* *}$ & $0,316^{* *}$ & $0,257^{* *}$ & $0,020^{* *}$ & $0,291^{* *}$ & - \\
\hline Amb & $-0,529^{* *}$ & $0,284^{* *}$ & $0,285^{* *}$ & $-0,410^{* *}$ & $-0,164^{* *}$ & $-0,295^{* *}$ & $-0,693^{* *}$ & $-0,615^{* *}$ & $0,343^{* *}$ & 0,021 & $-0,346^{* *}$ \\
\hline
\end{tabular}

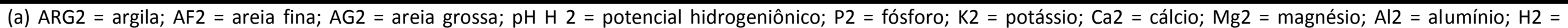

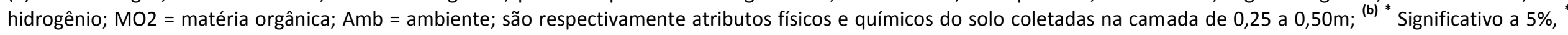
Significativo a $1 \%$ 
O Ambiente se relaciona positivamente com todos os atributos e profundidades, exceto Hidrogênio. Nota-se que 0 atributo Ambiente apresenta comportamento inversamente proporcional aos teores de fósforo, potássio, magnésio e matéria orgânica, pois conforme aumenta a profundidade de amostragem, os teores de matéria orgânica e os demais nutrientes reduzem concomitantemente ao aumento nos teores de alumínio, hidrogênio e acidificação do meio.
A variabilidade de diversos atributos do solo é dependente de fatores de sua formação e relacionado com o seu manejo (SOUZA et al., 2001), sendo influenciada pela sua localização na paisagem ou no declive (MARQUES JÚNIOR, 1995). Assim, podemos observar no Quadro 4 os parâmetros dos semivariogramas simples ajustados para os atributos estudados para avaliar o cultivo de cana de açúcar na região do Pontal do Paranapanema.

Quadro 4. Parâmetros dos semivariogramas simples ajustados dos atributos físico-químicos de solos cultivados com cana de açúcar na região do Pontal do Paranapanema - SP.

\begin{tabular}{|c|c|c|c|c|c|c|c|c|c|c|c|}
\hline \multirow{3}{*}{$\underset{\text { (a) }}{\text { Atributos }}$} & \multicolumn{11}{|c|}{ Parâmetros } \\
\hline & \multirow{2}{*}{$\begin{array}{c}\text { Modelo } \\
\text { (b) }\end{array}$} & \multirow{2}{*}{$\begin{array}{c}\text { Efeito } \\
\text { pepita } \\
\left(C_{0}\right)\end{array}$} & \multirow{2}{*}{$\begin{array}{l}\text { Patamar } \\
\qquad\left(\mathrm{C}_{0}+\mathrm{C}\right)\end{array}$} & \multirow{2}{*}{$\begin{array}{l}\text { Alcance } \\
\left(A_{0}\right)(m)\end{array}$} & \multirow{2}{*}{$r^{2}$} & \multirow{2}{*}{$S Q R^{(c)}$} & \multicolumn{2}{|c|}{$A D E^{(d)}$} & \multicolumn{3}{|c|}{ Validação cruzada } \\
\hline & & & & & & & $\%$ & Classe $^{*}$ & A & b & $r$ \\
\hline Arg1 & Epp & $6,128 \times 10^{-1}$ & $6,128 \times 10^{-1}$ & - & - & - & - & - & - & - & - \\
\hline AF1 & $\operatorname{Exp}(38)$ & $1,090 \times 10^{-1}$ & $1,211 \times 10^{-2}$ & 840 & 0,22 & $4,070 \times 10^{3}$ & 91 & MA & $-10,81$ & 1,234 & 0,4647 \\
\hline AG1 & $\operatorname{Exp}(1130)$ & $4,260 \times 10^{-1}$ & $1,571 \times 10^{-2}$ & 2460 & 0,873 & $4,810 \times 10^{2}$ & 73 & $A$ & 2,49 & 0,916 & 0,563 \\
\hline pH 1 & $\operatorname{Exp}(1130)$ & $1,461 \times 10^{-1}$ & $2,932 \times 10^{-1}$ & 5520 & 0,951 & $7,484 \times 10^{4}$ & 50 & $M$ & 0,26 & 0,958 & 0,5495 \\
\hline P1 & $\operatorname{Exp}(1130)$ & $0,188 \times 10$ & $1,849 \times 10$ & 1860 & 0,837 & $0,853 \times 10^{1}$ & 90 & MA & 0,71 & 0,893 & 0,5567 \\
\hline K1 & Esf (1098) & $2,000 \times 10^{-4}$ & $2,874 \times 10^{-1}$ & 1660 & 0,879 & $2,698 \times 10^{-3}$ & 96 & MA & 0,04 & 0,909 & 0,6503 \\
\hline Ca1 & $\operatorname{Exp}(1385)$ & $4,480 \times 10^{-1}$ & $1,222 \times 10^{1}$ & 2280 & 0,601 & $1,410 \times 10^{-1}$ & 91 & MA & 0,03 & 0,990 & 0,6587 \\
\hline Mg1 & Exp (1433) & $2,110 \times 10^{-2}$ & $1,892 \times 10^{-1}$ & 1770 & 0,522 & $3,048 \times 10^{-3}$ & 88 & MA & 0,08 & 0,907 & 0,5244 \\
\hline Al1 & Epp & $2,804 \times 10^{-2}$ & $2,804 \times 10^{-2}$ & - & - & - & - & - & - & - & - \\
\hline H1 & $\operatorname{Exp}(1130)$ & $4,890 \times 10^{-2}$ & $3,258 \times 10^{-1}$ & 1710 & 0,772 & $2,727 \times 10^{-3}$ & 85 & MA & 0,43 & 0,742 & 0,4147 \\
\hline MO1 & $\operatorname{Exp}(1103)$ & $2,000 \times 10^{-4}$ & $1,054 \times 10^{-1}$ & 1860 & 0,638 & $6,030 \times 10^{-4}$ & 91 & MA & 0,10 & 0,910 & 0,5932 \\
\hline Arg2 & Exp (1123) & $1,000 \times 10^{-1}$ & $4,240 \times 10$ & 1740 & 0,767 & 6,33 & 99 & MA & 1,49 & 0,94 & 0,8012 \\
\hline AF2 & $\operatorname{Exp}(1130)$ & $0,750 \times 10$ & $1,197 \times 10^{2}$ & 1380 & 0,646 & $6,16 \times 10^{2}$ & 94 & MA & 1,60 & 0,959 & 0,7071 \\
\hline AG2 & Esf (1130) & $6,090 \times 10^{1}$ & $1,219 \times 10^{2}$ & 2990 & 0,825 & $4,46 \times 10^{2}$ & 50 & $M$ & $-0,06$ & 1,000 & 0,7489 \\
\hline pH 2 & $\operatorname{Exp}(1568)$ & $4,170 \times 10^{-2}$ & $3,320 \times 10^{-1}$ & 1890 & 0,792 & $2,227 \times 10^{-3}$ & 87 & MA & 1,63 & 0,718 & 0,6723 \\
\hline P2 & Exp (1038) & $5,060 \times 10^{-1}$ & $0,321 \times 10^{1}$ & 2910 & 0,922 & $2,04 \times 10^{-1}$ & 84 & MA & 0,41 & 0,904 & 0,7867 \\
\hline K2 & Esf (1130) & $3,280 \times 10^{-2}$ & $1,056 \times 10^{-1}$ & 2640 & 0,864 & $4,225 \times 10^{-4}$ & 69 & $A L$ & 0,01 & 0,938 & 0,7713 \\
\hline $\mathrm{Ca} 2$ & $\operatorname{Exp}(1000)$ & $1,600 \times 10^{-2}$ & $3,560 \times 10^{-1}$ & 1770 & 0,508 & $4,929 \times 10^{-5}$ & 50 & $M$ & 0,04 & 0,976 & 0,7861 \\
\hline Mg2 & Gau (1130) & $2,000 \times 10^{-4}$ & $7,990 \times 10^{-2}$ & 831,38 & 0,794 & $1,033 \times 10^{-4}$ & 99 & MA & 0,21 & 0,586 & 0,7286 \\
\hline Al2 & Exp (1099) & $2,385 \times 10^{-2}$ & $4,780 \times 10^{-1}$ & 7170 & 0,897 & $4,929 \times 10^{-5}$ & 50 & $M$ & 0,00 & $-1,015$ & 0,7169 \\
\hline $\mathrm{H} 2$ & Esf (1034) & $2,270 \times 10^{-1}$ & $4,550 \times 10^{-1}$ & 3400 & 0,852 & $6,050 \times 10^{-3}$ & 50 & $M$ & $-0,05$ & 1,025 & 0,7204 \\
\hline MO2 & $\operatorname{Exp}(1041)$ & $5,000 \times 10^{-3}$ & $4,350 \times 10^{-2}$ & 2910 & 0,867 & $7,039 \times 10^{-5}$ & 88 & MA & 0,03 & 0,967 & 0,8018 \\
\hline Amb & $\operatorname{Exp}(1103)$ & $1,000 \times 10^{-2}$ & $6,720 \times 10^{-1}$ & 1350 & 0,702 & $1,38 \times 10^{-2}$ & 99 & MA & 0,04 & 0,983 & 0,8037 \\
\hline
\end{tabular}

(a) $\mathrm{ARG}=$ argila; $\mathrm{AF}=$ areia fina; $\mathrm{AG}=$ areia grossa; $\mathrm{pH}=$ potencial hidrogeniônico em água; $\mathrm{P}=$ fósforo; $\mathrm{K}=\mathrm{potássio;} \mathrm{Ca}=$ Cálcio; $\mathrm{Mg}$ = Magnésio; $\mathrm{Al}=$ alumínio; $\mathrm{H}$ = hidrogênio; $\mathrm{MO}$ = matéria orgânica, de 1 a 2 são respectivamente atributos físicos e químicos do solo coletadas na camada de 0,0 a $0,25 \mathrm{~m}$ e 0,25 a 0,50m; ( ${ }^{\text {b) }}$ Modelo: epp = efeito pepita puro, exp = exponencial, esf = esférico, gau = gaussiano. ${ }^{\text {(c) }} \mathrm{SQR}=$ soma de quadrado de resíduos; ${ }^{(\mathrm{d})} \mathrm{ADE}=$ avaliador de dependência espacial: $\mathrm{M}=$ média; $\mathrm{A}=$ alta; $\mathrm{MA}=$ muito alta.

Para a primeira profundidade $(0,00-0,25 \mathrm{~m})$, o atributo que apresentou maior dependência espacial foi $\mathrm{K}(96 \%), \mathrm{r}^{2}$ de 0,879 , soma de quadrado de resíduo aproximadamente $0\left(S Q R=2,698 \times 10^{-3}\right)$ e modelo esférico, cujo alcance foi de $1.660,0 \mathrm{~m}$ (Quadro 4). Ajustes com parâmetros similares ocorreram para $\mathrm{Ca}$ e $\mathrm{MO}$, na profundidade de 0,00-
$0,25 \mathrm{~m}$, com magnitude próximo de $0 \quad(S Q R=$ $7,876 \times 10^{-3}$ e $5,360 \times 10^{-4}$, respectivamente), porém com modelos Gaussiano para Ca e MO, com alcances de 2280,0 a 1860,0m para Ca e MO (Quadro 4). De acordo com o critério de Cambardella et al. (1994), a maioria dos parâmetros na menor profundidade indicam forte dependência espacial, com exceção do 
atributo $\mathrm{pH}$, que apresentou dependência espacial média.

Mondo et al. (2012), estudando a variabilidade espacial da fertilidade do solo e a relação com o potencial fisiológico de sementes de Campos Novos Paulistas-SP por meio de ferramentas de Geoestatística, não observaram correlação significativa entre os diferentes teores de fósforo e potássio no solo, ao obter ajuste gaussiano para semivariograma do atributo $\mathrm{K}$, com dependência espacial moderada ( $A D E=27 \%$ ) e alcance $422,7 \mathrm{~m}$, o que não ocorreu no presente trabalho. Entretanto, Araújo et al. (2016), avaliando a distribuição espacial da condutividade elétrica e atributos físicosquímicos em uma malha irregular com 588 pontos distribuídos aleatoriamente em um talhão de 150 ha de um Latossolo Vermelho Amarelo distrófico na camada de 0,00 a $0,20 \mathrm{~m}$, observaram que a variável que apresentou maior dependência espacial foi MO (ADE $=90 \%), r^{2}$ igual a 0,981, modelo exponencial com alcance de $954 \mathrm{~m}$ e SQR aproximadamente 0 $\left(5,627 \times 10^{-5}\right)$.

$\mathrm{Na}$ maior profundidade do solo $(0,25-0,50$ $\mathrm{m})$ foi possível observar que $\mathrm{o}$ atributo $\mathrm{P}$ obteve $\mathrm{O}$ maior coeficiente de determinação espacial $\left(r^{2}=\right.$ 0,922), ou seja, o melhor ajuste semivariográfico, com avaliador da dependência espacial muito alto $(A D E=86 \%)$, com alcance de 2910,0 m e ajuste exponencial. De acordo com Cambardella et al. (1994) os atributos que apresentam forte dependência especial são mais influenciados pelas propriedades intrínsecas do solo, como textura e mineralogia, enquanto aquelas que apresentam fraca dependência são influenciadas por propriedades extrínsecas do solo, como o cultivo e a aplicação de fertilizantes, ou seja, são dependentes do manejo do solo.

O alcance é o principal parâmetro fornecido pela geoestatística, representa a distância em que uma variável sinaliza continuidade espacial sendo que, a partir desta distância, o comportamento espacial da variável passa a ser totalmente aleatório (LEMOS FILHO et al., 2008). No presente estudo, os valores do alcance foram acima de $800 \mathrm{~m}$ para o semivariograma simples (Quadro 4) e $900 \mathrm{~m}$ para o semivariograma cruzado (Quadro 5), sendo de suma importância para a agricultura de precisão uma vez que os programas computacionais o utilizam para poder monitorar o maquinário agrícola quando da aplicação de insumos com taxas variáveis (DALCHIAVON et al., 2011).

Quadro 5. Parâmetros dos semivariogramas cruzados ajustados dos atributos físico-químicos de solos cultivados com cana de açúcar na região do Pontal do Paranapanema - SP.

\begin{tabular}{|c|c|c|c|c|c|c|c|c|c|c|c|}
\hline \multirow{3}{*}{ Atributos $^{(a)}$} & \multicolumn{11}{|c|}{ Parâmetros } \\
\hline & \multirow{2}{*}{$\underset{\text { (b) }}{\text { Modelo }}$} & \multirow{2}{*}{$\begin{array}{l}\text { Efeito } \\
\text { pepita } \\
\left(C_{0}\right)\end{array}$} & \multirow{2}{*}{$\begin{array}{l}\text { Patamar } \\
\left(C_{0}+C\right)\end{array}$} & \multirow{2}{*}{$\begin{array}{l}\text { Alcance } \\
\left(A_{0}\right)(m)\end{array}$} & \multirow[b]{2}{*}{$r^{2}$} & \multirow[b]{2}{*}{$S Q R^{(c)}$} & \multicolumn{2}{|c|}{$A D E^{(d)}$} & \multicolumn{3}{|c|}{ Validação cruzada } \\
\hline & & & & & & & $\%$ & Classe $^{*}$ & a & b & $\mathbf{r}$ \\
\hline \multicolumn{12}{|c|}{$\mathrm{Y}(\mathrm{h})$ cruzado } \\
\hline \multicolumn{12}{|c|}{ Profundidade $0,00-0,25 \mathrm{~m}$} \\
\hline$A m b=f(K)$ & $\exp (1544)$ & $-3,000 \times 10^{-4}$ & $-1,566 \times 10^{-1}$ & 1800,0 & 0,371 & $4,238 \times 10^{-3}$ & 99,0 & $A L$ & $-0,700$ & 1,181 & 0,6066 \\
\hline$A m b=f(C a)$ & $\exp (1482)$ & $-3,000 \times 10^{-3}$ & $-5,810 \times 10^{-1}$ & 2430,0 & 0,790 & $1,030 \times 10^{-2}$ & 99,0 & $A L$ & $-0,790$ & 1,205 & 0,6284 \\
\hline$A m b=f(M g)$ & $\exp (1075)$ & $-4,000 \times 10^{-4}$ & $-1,778 \times 10^{-1}$ & 1920,0 & 0,732 & $1,839 \times 10^{-3}$ & 99,0 & $A L$ & 0,620 & 0,827 & 0,6511 \\
\hline$A m b=f(M O)$ & $\exp (962)$ & $-1,000 \times 10^{-4}$ & $-8,620 \times 10^{-2}$ & 1620,0 & 0,385 & $5,410 \times 10^{-3}$ & 99,0 & $A L$ & 0,600 & 0,832 & 0,656 \\
\hline \multicolumn{12}{|c|}{ Profundidade $0,25-0,50 \mathrm{~m}$} \\
\hline$A m b=f(A R G)$ & esf (1103) & $-9,410 \times 10^{-1}$ & $-2,118 \times 10^{6}$ & 1510,0 & 0,570 & $2,390 \times 10^{-1}$ & 55,6 & M & 0,610 & 0,829 & 0,8099 \\
\hline$A m b=f(A F)$ & esf (1103) & $8,340 \times 10^{-1}$ & $1,866 \times 10^{6}$ & 920,0 & 0,210 & $1,620 \times 10^{-1}$ & 55,3 & $M$ & 0,610 & 0,829 & 0,8099 \\
\hline$A m b=f(A G)$ & $\exp (1103)$ & $9,120 \times 10^{-1}$ & $2,134 \times 10^{6}$ & 9750,0 & 0,894 & $1,130 \times 10^{-1}$ & 57,3 & $M$ & 0,610 & 0,829 & 0,8099 \\
\hline$A m b=f(K)$ & $\exp (1430)$ & $-1,000 \times 10^{-4}$ & $-7,760 \times 10^{-2}$ & 1980,0 & 0,411 & $1,149 \times 10^{-3}$ & 99,0 & $A L$ & 0,610 & 0,829 & 0,8099 \\
\hline$A m b=f(C a)$ & $\exp (1734)$ & $-5,000 \times 10^{-4}$ & $-2,570 \times 10^{-1}$ & 2010,0 & 0,777 & $1,865 \times 10^{-3}$ & 99,0 & $\mathrm{AL}$ & 0,830 & 0,774 & 0,9088 \\
\hline$A m b=f(M g)$ & $\exp (1103)$ & $-1,000 \times 10^{-4}$ & $-1,312 \times 10^{-1}$ & 1680,0 & 0,667 & $9,933 \times 10^{-4}$ & 99,0 & $A L$ & 0,610 & 0,829 & 0,8099 \\
\hline
\end{tabular}

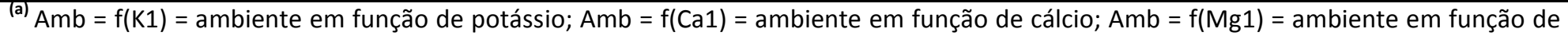
magnésio; $A m b=f(M O 1)=$ ambiente em função de matéria orgânica; $A m b=f(A R G 1)=$ ambiente em função de argila; $A m b=f(A F 1)=$ ambiente em função de areia fina, e $A m b=f(A G 1)=$ ambiente em função de areia grossa, de 1 a 2 são respectivamente atributos físicos e químicos do solo coletadas na camada de 0,0 a 0,25m e 0,25 a 0,50m; ${ }^{\text {(b) }}$ Modelo: exp = exponencial, esf = esférico, gau = gaussiano. ${ }^{\text {(c) }}$ SQR = soma de quadrado de resíduos; ${ }^{(\mathrm{d})} \mathrm{ADE}=$ avaliador de dependência espacial: $\mathrm{M}=$ média; $\mathrm{A}=$ alta; $\mathrm{MA}=$ muito alta.
} 
Com referência a este parâmetro avaliativo, areia grossa $(9750 \mathrm{~m})$ forneceu o maior valor de alcance, com modelo exponencial enquanto a variável dependente areia fina apresentou menor valor $(920,0 \mathrm{~m})$, ambos em subsuperfície, sugerindo que em trabalhos futuros com o mesmo intuito e condições, o alcance empregado não seja inferior a este valor. Esta informação é de suma importância, pois quando os valores de espaçamento encontrados são maiores que os espaçamentos utilizados para amostragem, assim como no presente estudo, indicam que as amostras estão correlacionadas espacialmente umas às outras, permitindo o uso de interpolação (VIERA et al., 2007; ZONTA et al., 2014).

Nas figuras 1a, 1b, 1c, 1d, 2a, 2b, 2c, 2d, 2e, estão contidos os semivariogramas cruzados e nas figuras 3a, 3b, 3c, 3d, 4a, 4b, 4c, 4d, estão contidos os mapas de cokrigagem entre os atributos que apresentaram dependência espacial entre si. Atestando a inter-relação espacial do ambiente
(AMB) com os atributos do solo, $\mathrm{K}, \mathrm{Ca}, \mathrm{Mg}$ e $\mathrm{MO}$ na profundidade de 0,00-0,25m e ARG, AF, AG, K, Ca, $\mathrm{Mg}$ na profundidade de $0,25-0,50 \mathrm{~m}$, resultaram em cokrigagem, evidenciando que a variabilidade espacial dos atributos físicos e químicos foram explicados de acordo com variabilidade espacial do ambiente (AMB).

Comparando os semivariogramas simples e cruzados (Quadro 4 e Figuras 3) na profundidade de $0,00-0,25 \mathrm{~m}$, constatou-se que os atributos que apresentam correlação linear fornecem melhor ajuste por meio da cokrigagem em relação a krigagem simples, evidenciados por maiores ADE e maior $r^{2}$, exceto para Ca onde tais parâmetros foram maiores nos semivariogramas simples. Comportamento semelhante ocorreu na profundidade 0,25-0,50m, com valores de ADE variando de 50 a $99 \%$ no semivariograma simples e 55 a $99 \%$ no semivariograma cruzado, com exceção dos atributos $\mathrm{Ca}$ e $\mathrm{AG}$.

Figura 1. Semivariograma cruzado para ambiente de produção em função dos parâmetros químicos cálcio (Ca), potássio $(K)$, magnésio $(\mathrm{Mg})$ e matéria orgânica $(\mathrm{MO})$, respectivamente, $A m b=f(C a 1) ; A m b=f(K 1) ; A m b=f(M g 1)$; $A m b=f(M O 1)$ na camada de 0,00 a $0,25 m$ dos solos estudados.

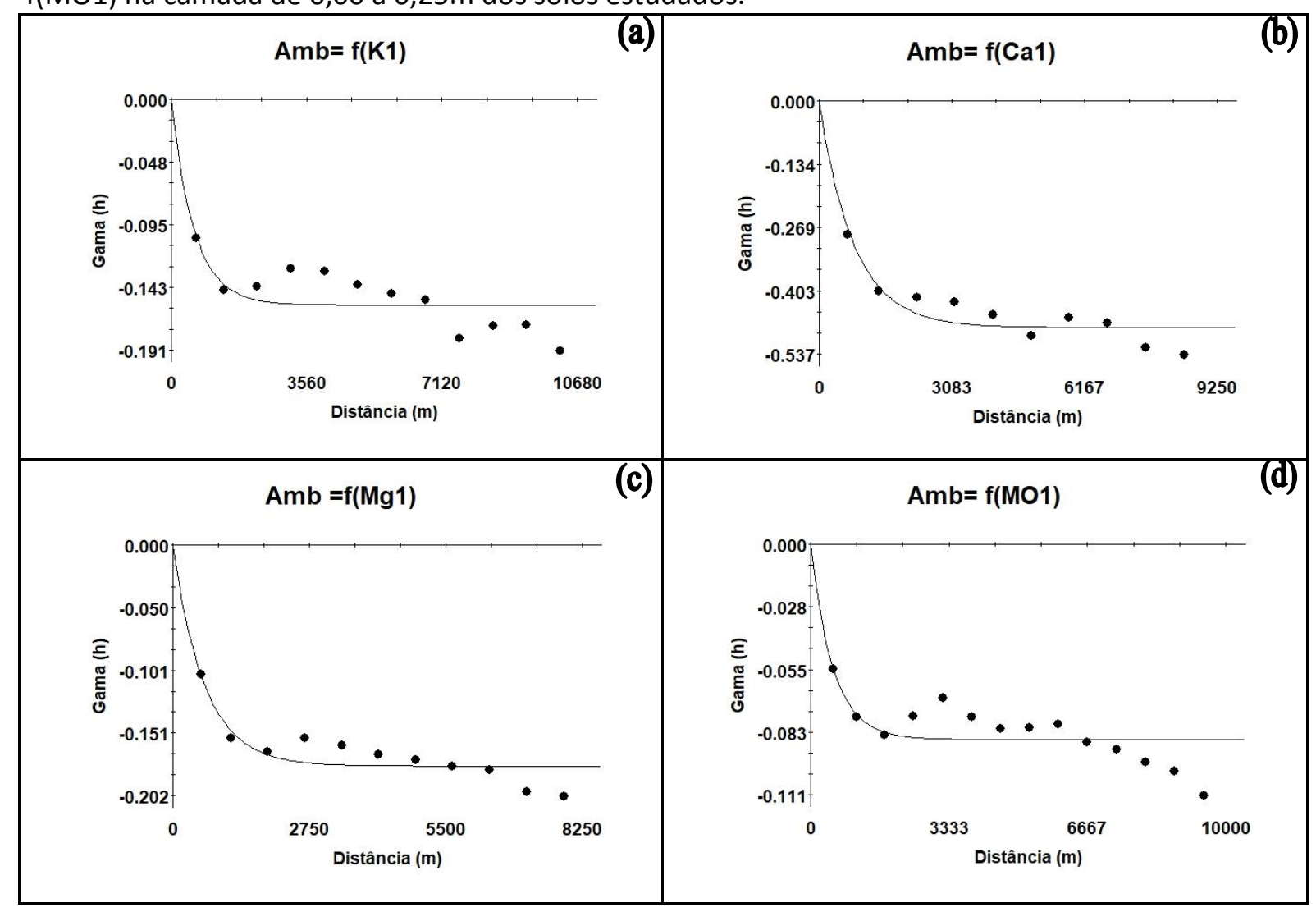

Corroborando com a afirmação acima, os altos valores de $A D E$ variam de médio a alto, sendo que na profundidade de $0,00-0,25 \mathrm{~m}$, todos os atributos apresentaram alta dependência espacial.
Tal fato é explicado pelo manejo adotado, preparo convencional, que nesta profundidade é mais efetivo, refletindo as técnicas utilizadas na implantação como a aplicação de fertilizantes e 
corretivos através dos teores de $\mathrm{Ca}, \mathrm{K}$ e $\mathrm{Mg}$, e a

meio dos teores de MO. cobertura vegetal e sistema radicular da planta por

Figura 2. Semivariograma cruzado para ambiente de produção em função dos parâmetros físicos argila (ARG), areia fina (AF) e químicos cálcio (Ca), potássio (K) e magnésio (Mg), respectivamente, $A m b=f(A R G 2)$; $A m b=$ $f(A F 2) ; A m b=f(C a 2) ; A m b=f(K 2)$ e $A m b=f(M g 2)$ na camada de 0,25 a 0,50m dos solos estudados.

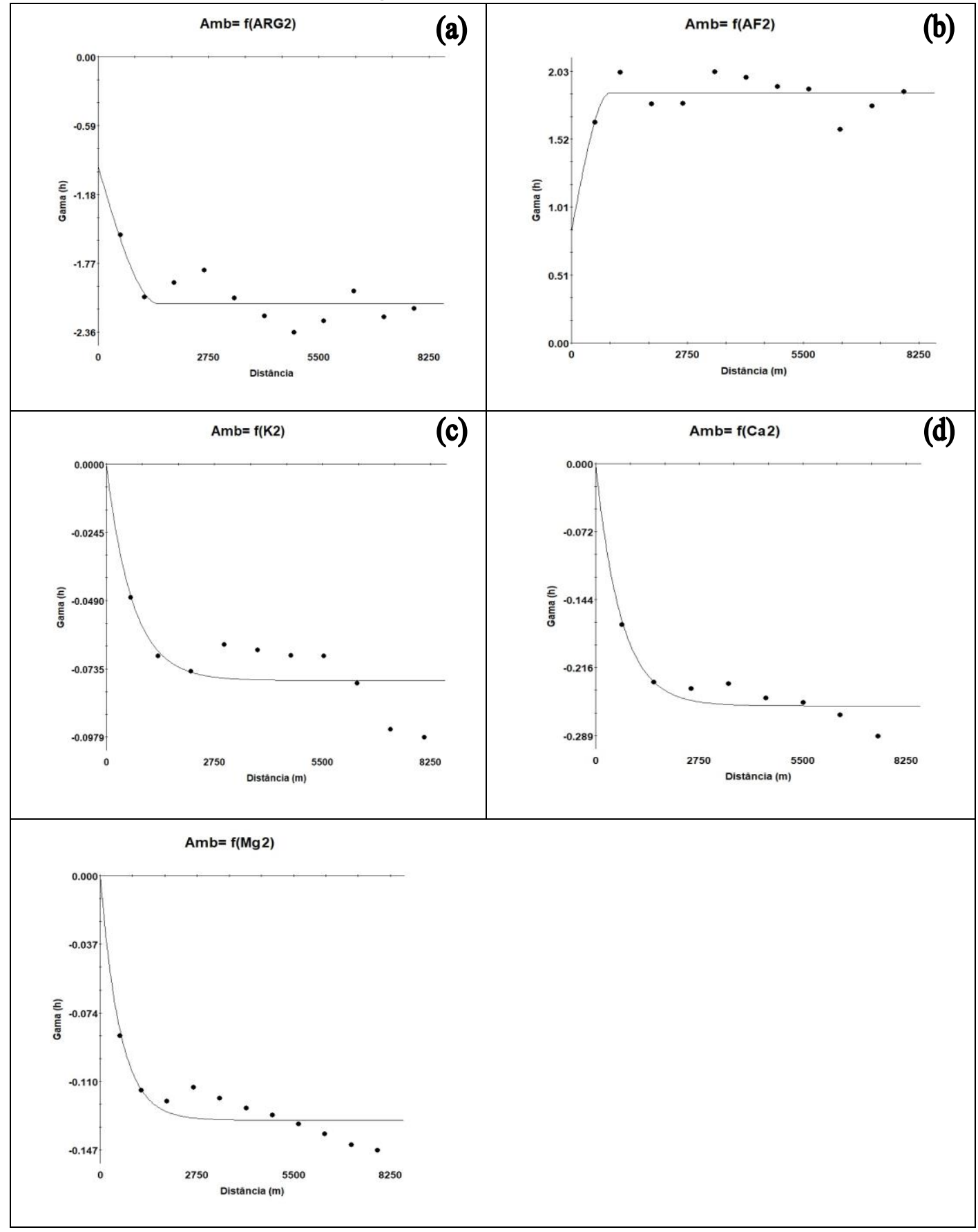

Nas Figuras 3 a,b,c,d, as co-krigagens diretas apresentaram menores teores de $\mathrm{MO}$ em zonas coincidentes com os menores teores de $\mathrm{Ca}, \mathrm{K}, \mathrm{Mg}$, elucidando a influência da $\mathrm{MO}$ na retenção de bases, pois solos com baixos teores de $\mathrm{MO}$ possuem menor capacidade de retenção e baixa capacidade de troca catiônica, sendo o inverso verdadeiro. Os atributos evidenciaram apreciável relação espacial direta e podem ser utilizados como indicadores de áreas especificas de manejo. Dalchiavon et al. (2013), estudando variabilidade espacial de atributos do solo e produtividade em cultivo de cana de açúcar observou comportamento semelhante para a MO. Tais resultados são análogos àqueles de Braga (2011), para a produtividade de colmos de cana-deaçúcar em função também do teor de matéria orgânica do solo. 
Figura 3. Mapas de Cokrigagem para ambiente de produção em função dos parâmetros químicos cálcio (Ca), potássio (K), magnésio (Mg) e matéria orgânica (MO), respectivamente, $A m b=f(C a 1) ; A m b=f(K 1) ; A m b=f(M g 1)$ e $A m b=f(M O 1)$ na camada de 0,00 a $0,25 m$ dos solos estudados.

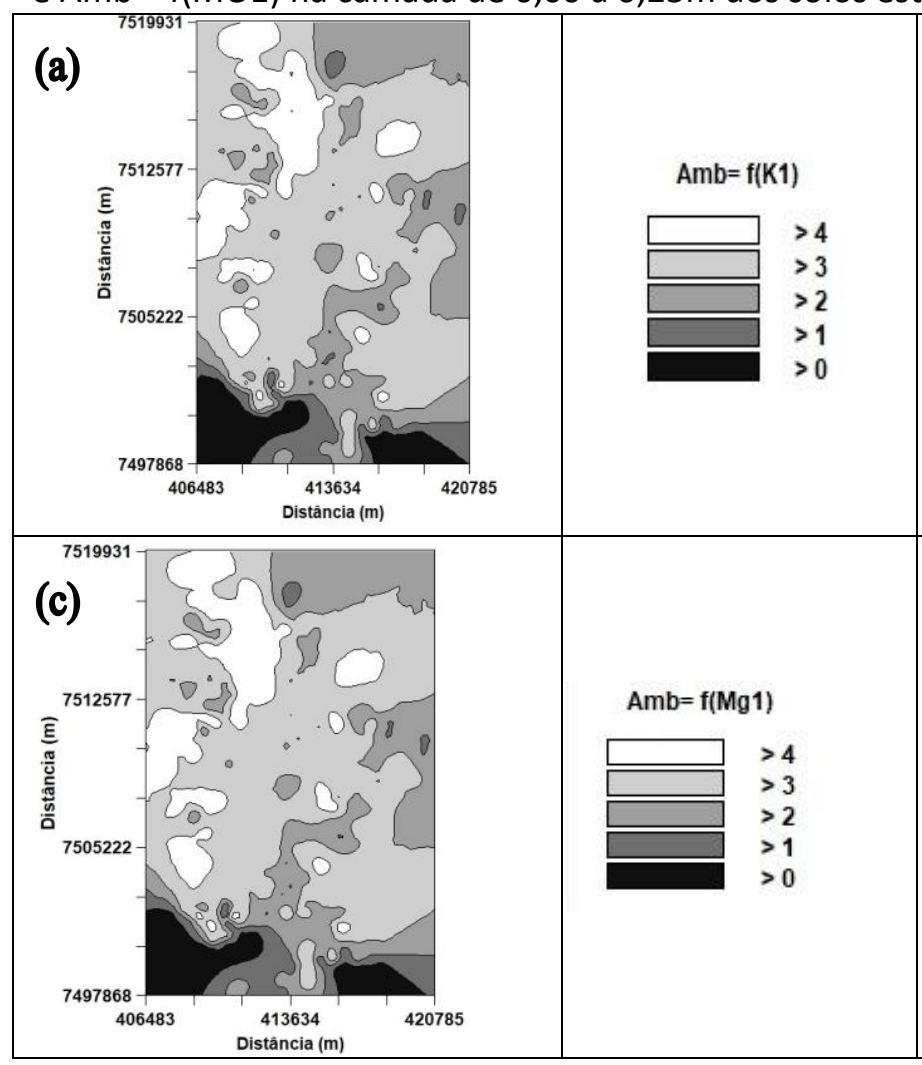

Em profundidade o mesmo comportamento para os atributos químicos e MO não são observados (Figuras 4 a,b,c,d), pois a matéria orgânica tem maior influência nos primeiros centímetros dos solos cultivados devido a deposição de material vegetal e manejo adotado. Em contrapartida, o mapa de argila apresenta distribuição semelhante aos demais atributos químicos e inverso aos teores de areia fina e grossa como esperado. (b)

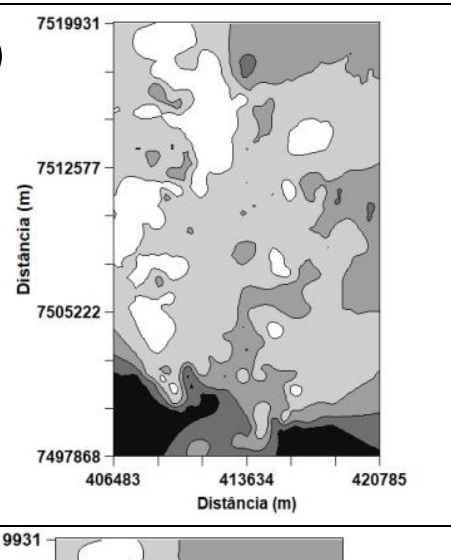

\section{$\mathrm{Amb}=\mathrm{f}(\mathrm{Ca} 1)$}

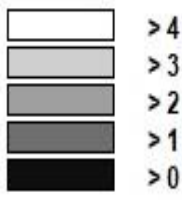

$A m b=f(M O 1)$

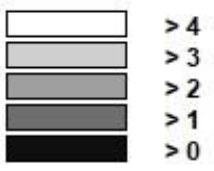

7497868

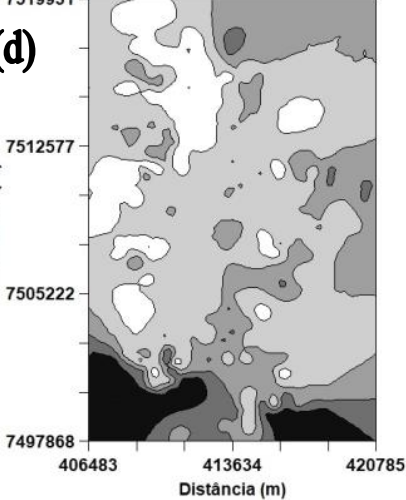

Neste contexto, a correlação entre o atributo Ambiente com os demais atributos do solo em subsuperfície explicita a influência da distribuição das frações formadoras do solo (areia fina, grossa e argila) sobre os demais atributos do solo em estudos com áreas extensas onde se torna possível observar as diferenças do relevo. 
Figura 4. Mapas de Cokrigagem para ambiente de produção em função dos parâmetros físicos argila (ARG2), areia fina (AF2) e químicos potássio (K) e cálcio (Ca), respectivamente, $A m b=f(A R G 2) ; A m b=f(A F 2) ; A m b=f(K 1)$ e Amb $=\mathrm{f}(\mathrm{Ca} 2)$ na camada de 0,25 a 0,50m dos solos estudados.

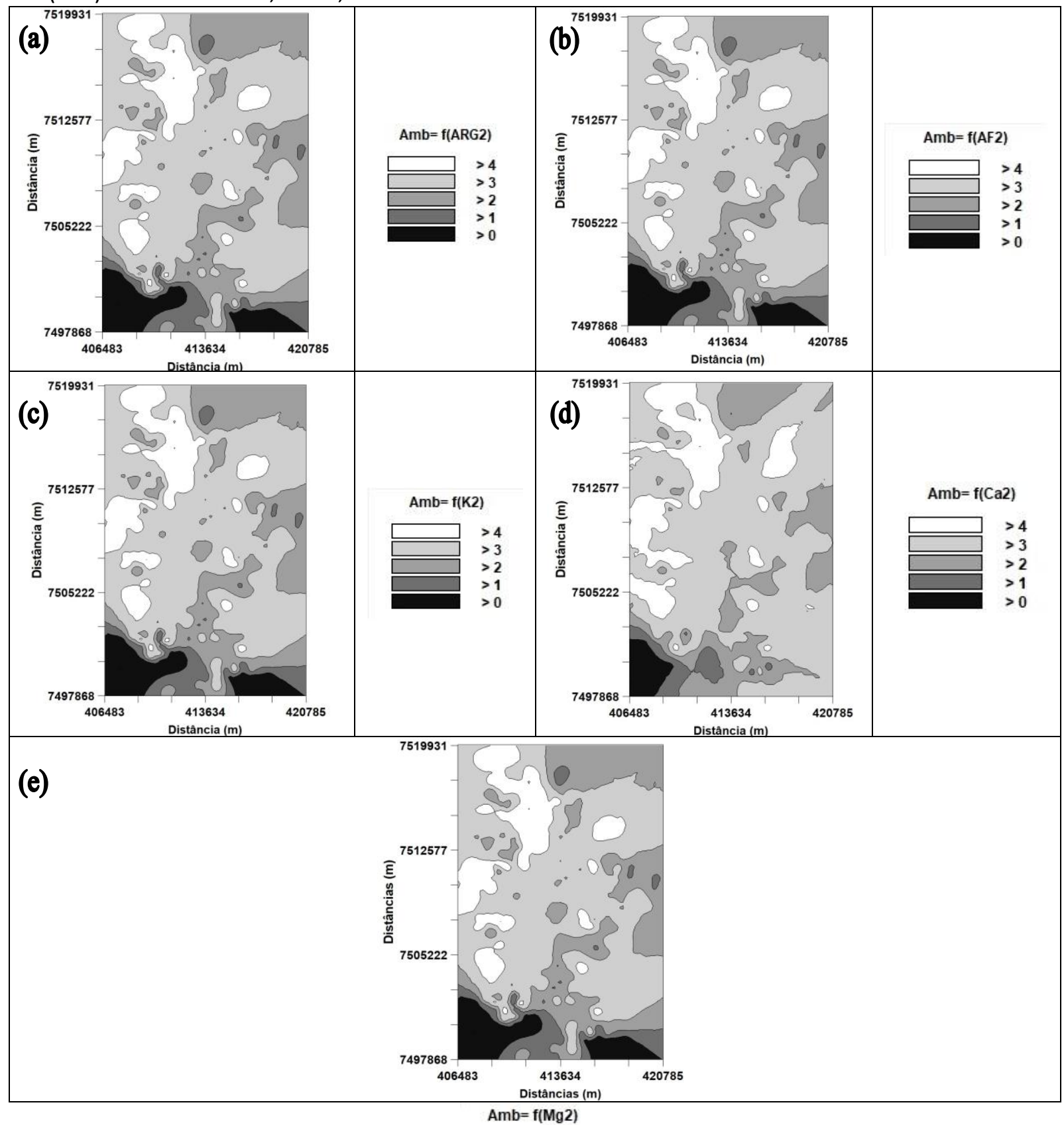

\section{CONCLUSÕES}

A dependência espacial encontrada nos 3 atributos químicos do solo analisados indie-me- $\mathrm{as}_{>0}^{11}$ variações espaciais devem ser consideradas no planejamento de coleta de amostras de solo e nas práticas de manejo do solo.

Dentre os atributos, o teor de alumínio foi o que apresentou maior coeficiente de variação.

Apenas o atributo ambiente correlacionouse com os demais atributos do solo.

\section{REFERÊNCIAS}

ARAÚJO, E.G.; CORREA, A.R.; LIMA, D.C.O.S.; PRANDO, E.P.; SENA, K.N.; MONTANARI, R.; SILVA, R.M. Análise espacial da condutividade elétrica e atributos físico-químicos de um Latossolo. Agrarian, v.9, n.31, p.73-83, 2016.

BRAGA, J. A. Inter-relações da produtividade de cana-de-açúcar com atributos físico-químicos de um Argissolo Vermelho eutrófico do noroeste paulista. 2011. Dissertação (Mestrado em Agronomia) - Faculdade de Engenharia. Universidade Estadual Paulista, Ilha Solteira, 2011. 
CAMBARDELLA, C.A.; MOORMAN, T.B.; NOVAK, J.M.; PARKIN, T.B.; KARLEN, D.L.; TURCO, R.F.; KONOPKA, A.E. Field-scale variability of soil properties in central lowa soils. Soil Science Society of American Journal, Madison, v.58, n.5, p. 1501-11, 1994. http://dx.do.org/10.2136/sssaj1994.0361599500580 $0050033 x$

CANASAT. Monitoramento da Cana-de-açúcar. 2013. Disponível em: http://www.dsr.inpe.br/laf/canasat/. Acesso em: 04 jul. 2018.

CARNEIRO, M.A.C.; ASSIS, P.C.R.; MELO, L.B.C.; PEREIRA, H.S.; PAULINO, H.B.; SILVEIRA NETO, A.N. Atributos bioquímicos em dois solos de Cerrado sob diferentes sistemas de manejo e uso. Pesquisa Agropecuária Tropical, v.38, n.4, p.276-283, 2008.

CRESSIE, N.A.C. Statistics for spatial data. New York: John Wiley \& Sons, 1991. 900p.

DALCHIAVON, F. C.; CARVALHO, M. P. E; NOGUEIRA, D. C.; ROMANO, D.; ABRANTES, F. L.; ASSIS, J. T.; OLIVEIRA, M. S. Produtividade da soja e resistência mecânica à penetração do solo sob sistema plantio direto no cerrado brasileiro. Pesquisa Agropecuária Tropical, v.41, p.8-19, 2011. https://doi.org/10.5216/pat.v41i1.8351

DALCHIAVON, F.C. Produtividade da cana-de-açúcar e definição de zonas específicas de manejo do solo. Semina: Ciências Agrárias, v.34, n.5, p.20772082, 2013. http://dx.do.org/10.5433/16790359.2013v34n5p2077

EMBRAPA. Manual de métodos de análises de solos. 2. ed. Campinas, Instituto Agronômico, 1983. 31p. (Boletim técnico, 81).

FERREIRA, M. M. Caracterização física do solo. In: LIER, Q. J. van. Física do solo. Viçosa: Sociedade Brasileira de Ciência do Solo, 2010. p. 1-28.

FREDDI, O.S.; CARVALHO, M.P.; VERONESI JÚNIOR, V.; CARVALHO, G.J. Produtividade do milho relacionada com a resistência mecânica à penetração do solo sob preparo convencional. Engenharia Agrícola, v.26, n.1, p.113-121, 2006. http://dx.doi.org/10.1590/S0100-

\section{3}

JOAQUIM, A. C.; DONZELLI, J. L.; QUADROS, A. C.; SARTO, L. F. Potencial de produção de cana-de- açúcar. In: SEMINÁRIOS COPERSUCAR DE TECNOLOGIA AGRONÔMICA, 7., 1997, Piracicaba. Anais... Piracicaba: Copersucar, 1997. p. 68-76.

LEMOS FILHO, L. C. A.; OLIVEIRA, E. L.; FARIA, M. A. DE; ANDRADE, L. A. de B. Variação espacial da densidade do solo e matéria orgânica em área cultivada com cana-de-açúcar (Saccharum officinarum L.). Revista Ciência Agronômica, v.39, n.2, p.193-202, 2008.

MARQUES JÚNIOR, J. Distribuição e atributos dos solos em relação à forma e evolução de uma vertente em Monte Alto. 1995. 226f. Tese (Doutorado em Agronomia), ESALQ-UPS, PiracicabaSP, 1995.

Meneguette, A. A. C. Atlas interativo do Pontal do Paranapanema: uma contribuição à educação ambiental. 2001. 190f. Tese (livre-docência) Universidade Estadual Paulista, Faculdade de Ciências e Tecnologia, 2001. Disponível em: <http://hdl.handle.net/11449/116073>.

MEURER, E. J. Fatores que influenciam o crescimento e o desenvolvimento das plantas. In: NOVAIS, R. F.; ALVAREZ V., V. H.; BARROS, N. F. de; FONTES, R. L. F.; CANTARUTTI, R. B.; NEVES, J. C. L. Fertilidade do solo. Viçosa: Sociedade Brasileira de Ciência do Solo, 2007. p. 65-90.

MONDO, V.H.V.; GOMES JUNIOR, F.G.; PINTO, T.L.F.; MARCHI, J.L.; MOTOMIYA, A.V.A.; MOLIN, J.P.; CICERO, S.M. Variabilidade espacial da fertilidade do solo e sua relação com o potencial fisiológico de sementes em área de produção de soja. Revista Brasileira de Sementes, v.34, n.2, p.193-201, 2012. http://dx.doi.org/10.1590/S010131222012000200002.

PIMENTEL-GOMES, F.; GARCIA, C.H. Estatística aplicada a experimentos agronômicos e florestais: exposição com exemplos e orientações pra uso de aplicativos. Piracicaba: Fealq, 2002. 309 p.

PRADO, H.; PÁDUA JÚNIOR, A. L. Ambientes de produção. In: RIPOLI, T. C. C.; RIPOLI, M. L. C.; CASAGRANDI, D. V.; IDE, B. Y. Plantio de cana-deaçúcar: estado da arte. Piracicaba: T. C. C. Ripoli, 2006. p. 157-172.

RAIJ, B.V.; QUAGGIO, J.A. Métodos de análise de solo para fins de fertilidade. Campinas: IAC, 1983. $39 \mathrm{p}$. 
ROBERTSON, G. P. GS $^{+}$: Geostatistics for Environmental Sciences. 7. ed. Michigan: Gamma Desing Software, 2004. 159 p.

SCHLOTZHAVER, S. D.; LITTELL, R. C. SAS: system for elementary statistical analysis. 2. ed. Cary: SAS, 1997. 441p.

SHAPIRO, S. S., WILK, M. B. An analysis of variance test for normality: complete samples. Biometrika, v.52, n.3/4, p.591-611, 1965. https://doi.org/10.2307/2333709

SILVA, L. R.; MENDONÇA, E. S. Matéria orgânica do solo. In: NOVAIS, R. F.; ALVAREZ V. V. H.; BARROS, N. F.; FONTES, R. L. F.; CANTARUTTI, R. B.; NEVES, J. C. L. Fertilidade do solo. Viçosa: Sociedade Brasileira De Ciência do Solo, 2007. p. 205-274.

SILVA, V. R.; REICHERDT, J. M.; STORCK, L.; FEIJÓ, S. Variabilidade espacial das características químicas do solo e produtividade de milho em um Latossolo Vermelho-Amarelo distrófico arênico. Revista Brasileira Ciência do Solo, v. 27, n.6, p.1013-1020, $2015 . \quad \quad$ http://dx.doi.org/10.1590/S0100$\underline{06832003000600005}$.

SMA-SP - SECRETARIA DE MEIO AMBIENTE DE SÃO PAULO). Pontal do Paranapanema: zoneamento ecológico-econômico. São Paulo: SMA/SP, 1999. Solos, 1997. 212p.

SORIA, J. E. Correlações lineares e espaciais entre atributos físico-químicos de solos de diferentes ambientes de produção de cana-de-açúcar no noroeste do Estado de São Paulo. 2014. 97f. Dissertação (Mestrado) - Universidade Estadual Paulista, Ilha Solteira, 2014.

SOUSA, D. M. G.; MIRANDA, L. N.; OLIVEIRA, S. A. Acidez do solo e sua correção. In: NOVAIS, R. F.; ALVAREZ V., V. H.; BARROS, N. F. de; FONTES, R. L. F.; CANTARUTTI, R. B.; NEVES, J. C. L. Fertilidade do solo. Viçosa: Sociedade Brasileira de Ciência do Solo, 2007. p. 205-274.

SOUZA, Z. M.; SILVA, M. L. S.; GUIMARÃES, G. L.; CAMPOS, D. T. S.; CARVALHO, M. P.; PEREIRA, G. T. Variabilidade espacial de atributos físicos em um Latossolo Vermelho Distrófico sob semeadura direta, em Selvíria, MS. Revista Brasileira de Ciência do Solo, v.25, n.3, p.699-707, 2001. http://dx.doi.org/10.1590/S0100-

06832001000300019 .
VELOSO, H. P.; RANGEL FILHO, A.L.R.; LIMA, J.C.A. Classificação da vegetação brasileira adaptada a um sistema universal. Rio de Janeiro: IBGE, 1991.

Recebido para publicação em 22/03/2018

Revisado em 03/07/2018

Aceito em 04/07/2018 